\title{
Inmigración peruana y pesca en el puerto de Cambados (Galicia): una perspectiva de género
}

Peruvian immigration and fishing in Cambados port (Galicia):

a gender perspective

\author{
María de los Ángeles Piñeiro Antelo \\ manxeles.pineiro@usc.es \\ Francisco Ramón Durán Villa \\ francisco.duran@usc.es \\ Xosé M. Santos \\ xosemanuel.santos@usc.es \\ Departamento de Geografía \\ Universidad de Santiago de Compostela (España)
}

\section{Resumen}

Desde los primeros años del siglo XX España es una potencia pesquera, donde se ha desarrollado una pesca industrial altamente competitiva y con un marcado carácter expansivo. Pero donde también la pesca artesanal en el litoral de país continúa manteniendo una importancia estratégica para las poblaciones locales. En Galicia resulta significativa la gran importancia socioeconómica de la pesca, el marisqueo y las actividades vinculadas al mundo de la mar, algo excepcional en el ámbito europeo. Este es el contexto en el que desde los últimos años de siglo XX se ha constatado un proceso de incorporación de inmigrantes a la actividad pesquera. En el año 2011 eran los peruanos los extranjeros más numerosos de los ocupados en la pesca en Galicia. Esta investigación tiene como objetivo principal realizar un estudio de caso centrado en el pequeño puerto de Cambados, para analizar los niveles de integración social de las mujeres de estos marineros peruanos. 
Palabras clave: pesca; inmigración; Perú; género; Galicia.

\begin{abstract}
Since the early part of the 20th century Spain has been a fishing power where expansive and highly competitive industrial fishing has developed and also a country where the traditional fishing on the coast is strategically important for the local population. In Galicia, the great socio-economic importance of fishing, shellfish-gathering and the activities related to the world of the sea is significant, something exceptional in Europe. This is the context in which, since the end of the 20th century, there has been a process of incorporation of migrants to the fishing activity. In 2011, Peruvian nationals were the most numerous foreigners employed by the fishing industry in Galicia. This research aims at making a case study, focused on the small port of Cambados, to analyze the levels of integration of wives of these Peruvian sailors.
\end{abstract}

Key words: fishing; migration; Peru; gender; Galicia.

Agradecimientos: Agradecer a la Cofradía de Pescadores San Antonio de Cambados su implicación y ayuda para la realización del trabajo de campo y de las entrevistas en las que se fundamenta este trabajo. Agradecer también al Director Provincial del ISM de Vilagarcía de Arousa su colaboración con esta investigación.

\title{
1 Introducción
}

Entre las características socio-económicas tradicionales que definen a Galicia hay dos aspectos que nos parecen relevantes para esta investigación: la pesca y la inmigración. En relación a la primera, desde tiempos remotos existen evidencias del uso de los recursos del mar gracias a la riqueza de sus aguas y arenales, y a un litoral muy recortado que favorece la instalación de puertos (Fernández, 1998; Vallejo, 2003). En la segunda mitad del siglo XVIII la pesca en Galicia y la industria relacionada con ella inicia un proceso de modernización que se acelera en la segunda mitad de la siguiente centuria (Romero, 2000). Es en este último momento cuando aparecen empresas de carácter transnacional y cuando los barcos de capital gallego se distribuyen por todos los caladeros del mundo (Alcaide, 1967; Hernández, 2007). Como veremos, esta fuerte expansión se enfrenta en la actualidad a grandes desafíos y a una notoria situación de crisis (Varela et al., 1997, 2003, 2010).

Una segunda característica recurrente en los tópicos sobre Galicia es el peso histórico de la emigración (Aldrey y Durán, 2011). La segunda mitad del siglo XIX atestigua fuertes corrientes migratorias hacia América Latina, fundamentalmente hacia Cuba, Argentina y Uruguay. La importancia de este movimiento provoca incluso que en algunos de los países citados cualquier 
inmigrante español sea llamado gallego. El final de la II Guerra Mundial sirvió para reanudar el proceso, en esta ocasión hacia Brasil, México y Venezuela. Sin embargo, el redireccionamiento más importante tuvo lugar hacia las ciudades industrializadas de España, como Bilbao, Barcelona o Madrid, y sobre todo hacia regiones europeas en proceso de rápido crecimiento, como Alemania, Francia y Suiza, entre otros (Hernández, 2002).

La inmigración extranjera comenzó a despuntar en Galicia en los últimos años del siglo XX, en un contexto de intensificación de este fenómeno en España, aunque con unas tasas más modestas, propias de un territorio periférico tanto en relación a España, como al resto del continente (González, 2008, 2010). Las relaciones entre pesca e inmigración se van a ver muy claramente en los años del tránsito entre los siglos XX y XXI. El mundo del mar vive una progresiva sustitución de trabajadores nativos por otros llegados de fuera. Primero se produce en la marina mercante con la llegada de marineros indonesios y filipinos fundamentalmente, que reemplazan a los europeos. Más tarde este proceso se extiende hacia la flota pesquera de altura y gran altura, en ocasiones como un fenómeno vinculado a la obligatoriedad de introducir trabajadores extranjeros en virtud de los acuerdos bilaterales de pesca con países no pertenecientes a la UE. Los barcos de bajura y artesanales muy vinculados con pequeñas empresas de carácter familiar pronto se van a encontrar con problemas de reclutamiento de mano de obra y no sólo por motivos económicos. Este proceso se ha generado por la falta de reemplazo generacional en los marineros de las comunidades costeras gallegas, debido a la escasa consideración social del oficio de marinero, a la dureza de las condiciones de trabajo en el mar, a la reducción de los márgenes de beneficio de dicha actividad, y sobre todo a la aparición de nuevas oportunidades de empleo en sectores en fuerte expansión a inicios del siglo XXI, como el turismo y la construcción (Etxaluze, 2000).

La dureza de las condiciones laborales en el mar, unos beneficios económicos menguantes, largas paradas biológicas y la oferta de empleo en sectores poco cualificados como la construcción, vaciaron los barcos de marineros locales. Muchos armadores gallegos tuvieron que recurrir a mano de obra de fuera procedente fundamentalmente de regiones de tradición pesquera, como algunas de Perú. Galicia que había sido tierra de emigrantes adquiere en la etapa de crecimiento de finales del siglo XX y principios del XXI un carácter receptor que aun siendo menor en intensidad al de otras regiones españolas, tiene ciertas peculiaridades, entre ellas la importancia que adquiere la pesca para la absorción de trabajadores foráneos procedentes de países como Marruecos, Cabo Verde, Perú o Senegal, entre otros.

Esta singularidad no ha sido, sin embargo, objeto de atención, al menos desde la geografía. No existen estudios geográficos que analicen las causas y consecuencias de este movimiento. En la producción científica española las migraciones han tenido un protagonismo singular con una abundante literatura que aborda esta cuestión (Reques y Cos, 2002; Villares y Fernández, 2006). Esto es especialmente relevante en la temática de género (Durán, 2009; Gregorio, 1998) donde ha 
habido una preocupación especial por el mercado laboral y por el papel de las mujeres en diferentes sectores económicos (García-Ramón, 1989; Cruz et al., 1994; Cánoves y Blanco, 2008). Sin embargo, la investigación geográfica sobre la pesca es muy escasa, como evidenció Santos en 2001. Más aún si nos referimos a trabajos que introduzcan la perspectiva de género en el ámbito pesquero (Santos, 2014, 2016). Son otras ciencias sociales las que han dedicado mayor atención a esta temática (García Negro, 2005; García Negro y Zotes, 2006; Santasmarinas, 2010)

El trabajo en el mar en Galicia, ha estado fuertemente segmentado, de tal manera que los hombres se ocuparon tradicionalmente de las labores en los barcos mientras que las mujeres realizaban importantes tareas complementarias en tierra (reparar redes, vender pescado, mariscar, ...) (Gago, 2004). Es objeto de este trabajo investigar si esos roles se reproducen entre las inmigrantes, y conocer su nivel de integración social en comunidades pesqueras de tamaño medio. Para ello realizamos un estudio de caso en el puerto de Cambados, en la provincia de Pontevedra, donde tiene importancia el colectivo de marineros originarios de Perú, trabajando fundamentalmente en la pesca del cerco, y donde se han realizado una serie de entrevistas en profundidad a las mujeres de estos inmigrantes.

\section{Galicia como potencia pesquera}

La producción pesquera de la Unión Europea supone algo más del 5 \% del total mundial, según datos del Parlamento Europeo (2014), aunque su flota pesquera se ha ido reduciendo de manera constante desde los últimos veinte años, debido a la necesidad de ajustar el esfuerzo pesquero a las posibilidades de pesca disponibles, y al desarrollo de nuevas potencias, como es el caso de algunos países ribereños del Pacífico de América del Sur.

El primer país de la Unión Europea en cuanto a su producción pesquera es España y su flota representa el $24 \%$ del arqueo total (TRB) de la UE (EUROSTAT, 2012). Ya desde los primeros años del siglo XX, en España se fue desarrollando una pesca industrial altamente competitiva, y con un marcado carácter expansivo, que convirtió a este país en una potencia en esta materia a nivel mundial. Así, después del fin de la Segunda Guerra Mundial, en los años centrales del siglo XX, la producción pesquera -fuertemente mermada durante los años del conflicto- empezaría a recuperarse y entraría en una fase expansiva propiciada por una legislación favorable a la construcción de buques, y por una línea de créditos oficiales destinados a modernizar la flota y a "explorar nuevas zonas y playas cualquiera que sea su distancia a nuestras costas" (Ley de Protección y Renovación de la flota mercante de 12 de mayo de 1956). Esta política expansionista hizo que en los años 1960 España llegase a contar con una de las mayores flotas pesqueras mundiales. Este desarrollo, vinculado especialmente con el despegue de los buques congeladores y la posibilidad de trabajar a gran distancia de los puertos base, se inició con el desarrollo de las 
pesquerías australes y permitió que España fuese el tercer productor mundial en pesca de gran altura, detrás de la URSS y Japón (Anuario FAO, 1971).

Este proceso de internacionalización de la pesca industrial española fue liderado por empresas y armadores gallegos - podemos citar el caso de Pescanova-, y supuso su llegada a caladeros de América del Sur en busca de nuevas oportunidades de pesca (Lobo, 1967). Junto con este fuerte crecimiento de la flota industrial, y pese a ser olvidada en las políticas desarrollistas de los años 1960, se ha mantenido un sector pesquero artesanal en el litoral de país, de gran importancia estratégica para las poblaciones locales (Hernández Borge, 2007).

Los procesos de territorialización del mar, la ampliación de las zonas económicas exclusivas, y la sobreexplotación de los caladeros tradicionales, han obligado al sector pesquero en Europa a afrontar un fuerte proceso de reconversión durante los últimos 30 años. Estos planes de ajuste de la capacidad han tenido como resultado la pérdida de peso económico y social de las actividades relacionadas con el mar (Lois, 1999; Varela, 2003).

Pero esta pérdida de importancia relativa de la economía pesquera ha sido menor en algunas áreas, calificadas por la UE como "altamente dependientes de la pesca", tal y como lo define el apartado 8 del artículo 4 del Reglamento (CE) 1260/1999 (3). Es el caso de Galicia, en el noroeste de la Península Ibérica, donde resulta muy significativo el peso de la pesca, el marisqueo y las actividades vinculadas al mundo de la mar (IGE, 2015). En esta comunidad, con 2732347 habitantes en 2015, tienen su puerto base 4739 embarcaciones, que suponen el $48 \%$ de todos los buques pesqueros españoles (Ministerio de Agricultura, Alimentación y Medio Ambiente, 2013). Se mantienen activos más de 80 puertos pesqueros y 62 lonjas donde se descargan y se realiza la primera venta de las capturas obtenidas. Y conviven pequeños puertos como Lira o Muros con una flota eminentemente artesanal, con otros donde existen infraestructuras portuarias de mayor peso, como ocurre en Vigo, A Coruña, Celeiro, Ribeira o Marín, que son base de grandes buques que faenan en caladeros de altura y gran altura en todo el mundo.

Como se ilustra en la Tabla 1, en la actividad pesquera de esta comunidad conviven sistemas de producción industriales con otros artesanales. Los buques destinados a la pesca industrial suponen la mitad del tonelaje existente, y el $33 \%$ de la potencia instalada en sus motores. Pero la pesca artesanal también cuenta con gran relevancia, ya que a ella se dedican el $95 \%$ de las embarcaciones con base en Galicia. 
Tabla 1. Flota pesquera con base en Galicia (2015)

\begin{tabular}{|l|l|c|c|c|}
\hline \multicolumn{2}{|c|}{ DESCRIPCIÓN } & $\begin{array}{c}\text { No } \\
\text { BARCOS }\end{array}$ & TRB & $\begin{array}{c}\text { POTENCIA } \\
\text { CV }\end{array}$ \\
\hline $\begin{array}{l}\text { PESQUERIA } \\
\text { INTERNACIONAL }\end{array}$ & Flota de Gran Altura & 113 & 48179 & 128156 \\
\hline PESQUERIA UE & Flota de Altura & 75 & 12875 & 46048 \\
\hline CALADERO ESPAÑOL & Flota litoral y artesanal & 4319 & 34026 & 209779 \\
\hline \multicolumn{2}{|r|}{ Totales } & 4507 & 95080 & 383983 \\
\hline \multicolumn{2}{|r|}{ BUQUES DEDICADOS A LA ACUICULTURA } & 1265 & & \\
\cline { 1 - 2 } &
\end{tabular}

Fuente: Registro de Buques Pesqueros de Galicia. Recuperado el 15 de enero de 2015

En el caso de la pesca industrial hay que destacar algunos proyectos empresariales centrados en el desarrollo de pesquerías experimentales en mares lejanos, en la investigación de barcos y motores más eficientes, o en la innovación en los sistemas de producción.

En cuanto a la pesca artesanal, que utiliza una amplia variedad de artes que se alternan de manera estacional en función de las especies objetivo, existen algunos ejemplos de modelos de gestión cooperativa de los recursos, en los que participan las instituciones locales, el sector -fundamentalmente a través de las organizaciones de pescadores (cofradías)-, las universidades públicas, y la propia administración autonómica, que suponen hitos en el desarrollo sostenible y en la conservación medioambiental en estos territorios costeros (García Allut, 1998 y 2005; Santos, 2000; Fernández-Vidal y Muiño, 2014).

Otra de las particularidades de esta Comunidad es la gran importancia socioeconómica que en ella tiene el marisqueo. Esta actividad presenta fundamentalmente dos modalidades: la extracción y el semicultivo principalmente de moluscos, crustáceos y equinodermos, con apoyo de embarcaciones, en zona marítimo-terrestre. Y el marisqueo a pie, en la franja intermareal, una actividad desarrollada casi exclusivamente por mujeres (Penas, 1998; Martínez et al., 1998; Pérez Pazó, 2010).

En cuanto al mercado de trabajo, los empleos en la pesca registran un descenso continuado desde comienzos de siglo en consonancia con la reducción del número y potencia de barcos pesqueros, pero también con la introducción de innovaciones tecnológicas para mejorar la seguridad y mecanizar el trabajo a bordo, con la reducción de las tripulaciones al mínimo requerido por razones técnicas y de seguridad, y por último con la progresiva eliminación, desde la segunda mitad de los años 1990, de las ayudas públicas para construir nuevos buques de pesca, o para crear empresas pesqueras (Piñeiro, 2010, 2015). 
En 2011 el n de tripulantes de la flota con base en Galicia ascendía a 12.552 personas, lo que representaba el 1,1\% do total de ocupados en la comunidad autónoma (Ocupesca, 2012). Aunque la mano de obra empleada en la pesca ha sido tradicionalmente procedente de la propia Galicia, el peso de los trabajadores extranjeros se ha ido incrementando al mismo tiempo que el despegue económico español ha propiciado la aparición de oportunidades de trabajo en otros sectores económicos, como la construcción o los servicios. En 2011 el 12,4\% de los tripulantes de los buques pesqueros con base en Galicia eran extranjeros, procedentes de países no pertenecientes a la UE en más del 80 \% de los casos. Estamos hablando de 1563 marineros, de los que el 55 \% trabajaban en el caladero español, pero que también estaban presentes en las embarcaciones que trabajan en aguas de la UE (27\%) y en caladeros internacionales (17\%). El colectivo más numeroso en este 2011 era el de peruanos (3,4\%), seguido de indonesios, marroquís, senegaleses y caboverdianos (Ocupesca, 2012). La crisis económica y la pérdida de oportunidades de empleo en las comunidades costeras han propiciado la reducción del número de trabajadores (Comisión Europea, 2016b), pero se ha producido un incremento de los tripulantes extranjeros, hasta alcanzar el 14,4\% del total de ocupados en el sector (Ocupesca, 2013)

El papel de las mujeres en el sector pesquero es complejo por la variedad de labores que éstas desarrollan, tanto en la economía formal como informal (Proyecto Áncora, 2012, 2012b). Dentro del sector formal, están presentes de manera testimonial en las actividades de pesca y marisqueo en embarcación (suponen un 4\% de los tripulantes según datos de Ocupesca 2012), actividades fuertemente masculinizadas. En cambio, su participación es mucho más fuerte, incluso hegemónica en algunos casos, en otras tareas vinculadas a las actividades extractivas y a las de servicios de apoyo al sector como el marisqueo a pie, la elaboración y reparación de redes, la acuicultura, la recolección de algas, y en el proceso de comercialización y distribución de productos pesqueros y marisqueros (García Negro, 2005; García Negro y Zotes, 2006; Marugán Pintos, 2010, 2010b).

En el sector informal, las mujeres se ocupan en muchos casos de tareas administrativas y de gestión de embarcaciones artesanales, y de otros trabajos que son comunes a los realizados en la economía formal, como la reparación de artes de pesca, o la venta y distribución de las capturas. Estas actividades "informales", no cuantificadas ni visibilizadas, contribuyen en buena medida al mantenimiento de la pesca artesanal como sistema productivo, por el ahorro que suponen a las pequeñas empresas pesqueras en costes de personal (Solsona, 1989; Proyecto Áncora, 2012).

En las últimas décadas, y en gran parte favorecido por el proceso de profesionalización de las mariscadoras, y del reconocimiento oficial de la profesión de redera, se ha asistido a un proceso de toma de conciencia de las mujeres como trabajadoras del mar (Santasmarinas, 2010). Han proliferado las asociaciones profesionales que procuran hacer visibles los problemas de las mujeres en un sector fuertemente masculinizado. Reflejo de esta evolución es la irrupción de las mujeres en 
los órganos de decisión de las cofradías de pescadores en Galicia. Así en el año 2013, según datos de la Federación de Cofradías de Pescadores de Galicia, 10 de las 62 cofradías de pescadores gallegas estaban presididas por una mujer, y en 18 de ellas ocupaban el cargo de vicepatrón mayor.

\section{Galicia, territorio de acogida}

A pesar de que los movimientos migratorios son consustanciales con el ser humano, las características de los mismos, sus patrones en los distintos momentos históricos, no dejan de ofrecernos nuevas situaciones, como ocurre con la creciente corriente de inmigrantes que elige España -y en particular Galicia- como territorio de acogida a medida que avanza la década de los años ochenta del siglo XX, extendiéndose al menos hasta el inicio de la crisis económica de 2008

Ante esta situación novedosa, tenemos que recurrir al análisis de las realidades a escalas mundo y estatal para comprender cómo el Estado español, casi sin concluir una larga y dilatada etapa emigratoria, se convierte en un país de inmigración. Así lo avala la promulgación de la Ley Orgánica 7/1985, de 1 de julio, sobre derechos y libertades de los extranjeros, modificada posteriormente en varias ocasiones - la más reciente en el 2013-, que responde más a los principios de una normativa de extranjería propiamente dicha (procedimientos administrativos de entrada y residencia) que a una ley de inmigración. La etapa de España como país emisor comienza en la segunda mitad de la centuria del diecinueve, con los desplazamientos masivos hacia Latinoamérica, en particular hacia Cuba y la Argentina y en menor medida hacia el Uruguay y Venezuela, destino este último tardío. Con Venezuela se cierra la etapa americana en los albores de la década del desarrollismo español - los años sesenta del siglo XX-, al tiempo que se inicia un nuevo éxodo masivo de trabajadores hacia los países centrales del capitalismo europeo en aquellos momentos, al amparo, cuando menos en teoría a tenor de los elevados índices de irregularidad, de la Ley de emigración de 1971 (Ley 33/1971, de 21 de julio). Esta Ley fue la última promulgada por un gobierno español hasta el presente: paradójicamente se mantuvo en vigor hasta la publicación de la Ley 40/2006, de 14 de diciembre, del Estatuto de la ciudadanía española en el exterior, veintiún años después de la reguladora de los que carecen de la nacionalidad española.

En el contexto del desarrollo del capitalismo global en el último tercio del siglo XX, la tendencia de los mercados y de las empresas a sobrepasar las fronteras nacionales se materializó en un crecimiento espectacular de los intercambios financieros y comerciales. Todo ello al compás de los procesos de desregulación y deslocalización desde los países del norte hacia los del sur. Al tiempo se genera un flujo de mano de obra en dirección contraria como consecuencia de la nueva división internacional del trabajo. No obstante, la lógica económica neoliberal, responsable por insolidaria de la génesis de una sociedad dual por la tendencia a la concentración de la riqueza en unos 
pocos países y en sectores muy minoritarios de la población, no tuvo su correlato en la libre circulación de las personas. Este tipo de movimiento se vio sometido a un creciente control gubernamental, por iniciativa propia o por directrices de la Unión Europea desde la firma del Tratado de Maastricht en 1992, por medio de normativas de extranjería, visados ${ }^{1}$, contratos en origen por medio de la fijación de cupos migratorios para trabajadores extranjeros no comunitarios $^{2}$, y regularizaciones ${ }^{3}$. Los principios de estabilidad e integración de los inmigrantes no fueron ajenos tampoco a las políticas de estos años: el Consejo de Ministros de 2 de diciembre de 1994 aprueba el I Plan para la Integración Social de los Inmigrantes ${ }^{4}$; se modifican competencias y se transforman y crean organismos ad hoc ${ }^{5}$, y se aprueba un nuevo Reglamento de inmigración (Real Decreto 155/1996, de 2 de febrero), que introduce figuras nuevas procedentes de las normativas europeas, tales como los visados en tránsito o la devolución en frontera.

En este escenario global de liberalización y apertura, con repercusiones especialmente negativas para los mercados laborales nacionales de los países más desfavorecidos, se insertan los flujos crecientes de salida del ámbito territorial latinoamericano desde principios de los años 1990. Estos movimientos se ven intensificados por los efectos socioeconómicos negativos que se derivan de la implantación de los planes de ajuste estructural impuestos por el Fondo Monetario Internacional en respuesta a la crisis de la década precedente - la década perdida-, cuyas consecuencias llevaron al empleo femenino a alcanzar altas cotas de subempleo y precariedad, por la imperiosa necesidad de aminorar la caída de ingresos de la unidad familiar, dando una especial difusión a la noción feminización de la pobreza, acuñada en Estados Unidos a finales de los años 1970. A las consecuencias de la recesión de los años 1980, tenemos que sumar los efectos socioeconómicos adversos de un orden social que, desde una lógica individualista y del interés por el beneficio

1 En 1991; se implanta el visado de entrada para los naturales de Marruecos, Argelia y Túnez; en 1992 a Perú; y en 1993 a Colombia.

2 El anuncio del establecimiento de los contingentes "cupos" a partir de 1993 fue efectuado por el director general de Política Interior, Fernando Puig de la Bellacasa, en el marco de las Jornadas Internacionales sobre Derecho de Asilo y Migraciones en la Comunidad Europea, celebradas en Madrid, que concluyeron con un llamamiento a los gobiernos para que aplicasen las leyes con flexibilidad, a la vista del desdibujamiento creciente de la frontera entre el refugiado y el emigrante que huye del hambre (El País, 26 de septiembre de 1992).

La contratación en origen de inmigrantes se realiza por medio del llamado contingente, dotado de permisos de trabajo y residencia de acuerdo con las necesidades productivas de las Comunidades Autónomas receptoras. Los cupos se destinarán a aquellas ocupaciones no atendidas por el mercado de mano de obra español; la oferta de puestos de trabajo -innominada generalmente- y el destino territorial, se establecen a partir de las ofertas de las empresas, mediante un proceso dialogado los representantes sindicales y de las organizaciones empresariales.

3 En virtud de lo previsto en la Ley de Extranjería se abrió un primer periodo de regularización en 1985, el segundo proceso extraordinario tuvo lugar en 1991.

4 Por medio del Plan se crean el Foro para la Integración Social de los inmigrantes (Real Decreto 490/1995, de 7 de abril) y el Observatorio Permanente de la Inmigración.

5 Es muy elocuente la transformación en 1991 del Instituto Español de Emigración en el Instituto de Migraciones, una Dirección General cuyas competencias se trasvasaron del Ministerio de Trabajo al Ministerio de Asuntos Sociales. También en ese año se crearon las Oficinas de Extranjeros y al año siguiente se crea la Comisión interministerial de Extranjería. 
propio, está generando importantes procesos de marginación y exclusión, procesos que han sido los principales responsables de la diversificación del universo de procedencia social de los inmigrantes, frente a los estereotipos y tópicos que en ocasiones se emplean (Maguid y Cerrutti, 2010). La quiebra del mundo sovietizante, que amplía el espacio de movilidad de la mano de obra hacia el este de Europa, la transformación del modelo chino y la difusión del convencimiento generalizado de que no existe otra alternativa -la conocida como ideología TINE (There is not alternative) - terminaron por acentuar estos movimientos de población, con una participación creciente de mujeres, que no dejan de ser más que el correlato de la pobreza en el tránsito de los siglos XX al XXI.

En los albores de los años noventa del siglo XX comienzan a percibirse los primeros síntomas del cambio en la tendencia migratoria española. De manera simultánea se corroboran los postulados de la teoría de los sistemas migratorios enunciada por el geógrafo Akin Mabogunje (1970) que introduce el punto de vista sistémico en el análisis de los procesos migratorios. Este marco explicativo es empleado y desarrollado posteriormente por Hania Zlotnik (1992), cuando afirma que los desplazamientos de población por motivos laborales a gran escala se organizan en torno a sistemas migratorios, es decir, por medio de los flujos de información, contactos personales y redes sociales. La interrelación entre los espacios de origen y de destino de las personas migrantes se veía reforzada en aquellos territorios que han tenido toda una serie de relaciones de intercambios comerciales, tecnológicos, culturales y simbólicos durante un largo período de tiempo, como ocurre en aquellos que han mantenido una prolongada etapa de relaciones coloniales. En nuestro caso sería aplicable a la corriente ultramarina en ambas las direcciones, un flujo bidireccional de población, aunque no coetáneo en tiempo y espacio, que por su magnitud sólo puede ser entendido y explicado en el marco de paradigmas y modelos relacionales -cadenas y redes migratorias- más dinámicos, que permiten reconstruir procesos sociales no contemplados por los tradicionales paradigmas individuales y estructurales (Castles, 2010, Castles y Kosack, 1973; Devoto, 1992; Pedone, 2002 y 2008; Villares, 1996). Además, el planteamiento sistémico introduce un matiz que no puede despreciarse, al afirmar que la corriente no sólo está compuesta por migrantes sensu strictu, sino también por estudiantado y turistas.

No obstante, los vínculos históricos en nuestro caso no serían suficientes de no haber coincido con un rápido, diversificado y elevado crecimiento de la economía española en esos años, liderado por el sector de la construcción, en un escenario demográfico caracterizado por el descenso de las tasas de fecundidad y natalidad; el consiguiente envejecimiento, que lleva asociado el aumento de los índices de dependencia -en particular en Galicia, como consecuencia de los efectos de la emigración secular-; y los avances de la formación en general y de la mujer en particular, con su incorporación decisiva al mercado de trabajo. Una situación sociodemográfica que nos permite vislumbrar a priori los nichos laborales en los que el aporte de los inmigrantes va a ser decisivo en 
los años venideros: trabajos de escasa cualificación y devaluados socialmente, difíciles de ocupar con mano de obra residente, sobre todo aquellos que están relacionados con el servicio doméstico y en particular con la atención personalizada a dependientes ubicados, salvo casos de enfermedad, en los dos extremos de la pirámide, lo que contribuyó decisivamente a los procesos de feminización de las corrientes inmigratorias y del mercado laboral español, tanto por los aportes de los contingentes de entrada como por facilitar la incorporación de las españolas en el mismo. Sin olvidar las repercusiones positivas sobre el rejuvenecimiento de la población española, por tratase de personas encuadradas mayoritariamente en el grupo etario de los adultos jóvenes (19-39 años) y por las pautas reproductivas de las mujeres inmigrantes, cuyos efectos ya se dejaron sentir en la natalidad en los albores de la década precedente (Domingo, 2004).

No es menos cierto que los gobiernos españoles, al igual que ocurrió en otros países occidentales europeos al término de la segunda guerra mundial (Francia o el Reino Unido, por ejemplo), establecieron estrategias de sustitución laboral y étnica en favor de ciertos colectivos de nacionales, en nuestro caso de personas procedentes de Latinoamérica - los preferidos- para limitar la presencia de otros grupos, en España de los naturales de África, con el fin de anular la dependencia de la mano de obra marroquí en la agricultura y la construcción, así como para eludir el choque cultural con otra religión (Izquierdo et al., 2002). La evolución del número de autorizaciones a los procedentes del otro lado del Atlántico y los procesos de regularización son un buen exponente de ello ${ }^{6}$, favorecido por las preferencias y las presiones de los empresarios en substituir la mano de obra norteafricana. Otras acciones de gobierno tales como la subscripción de convenios bilaterales de migración -que se sumarían a los de doble nacionalidad firmados a partir de finales de los años 1950 - con Estados latinoamericanos, la posibilidad de obtener la nacionalidad española a descendientes (hijos y nietos) de españoles, las mayores facilidades para obtener y renovar el permiso de residencia y el poder solicitar la nacionalidad española, después de dos años de residencia legal, avalan esta interpretación. Sólo los naturales de Perú vieron limitadas sus expectativas con la implantación del visado en $1992 .^{7}$ Sin embargo, este trato

6 En la Disposición transitoria segunda de la LO 7/1985 sobre Derechos y Libertades de los Extranjeros en España, se incluía la posibilidad de regularización para los extranjeros que se encontraban residiendo o trabajando en España en la fecha de entrada en vigor de la Ley. El periodo en el que se podía solicitar dicha regularización era de nueve meses durante los cuales se presentaron 43815 solicitudes. De ellos, 38181 fueron aprobados. El $37 \%$ pertenecía a africanos, $20 \%$ a americanos y $26 \%$ a europeos. En el de 1991 los africanos representaban ya el $56,9 \%$ de las solicitudes, siendo el $44 \%$ de todas las solicitudes marroquíes. Los inmigrantes procedentes de América representaban el $24,7 \%$ de las solicitudes y Asia el $11,47 \%$. Sin embargo, en la última de las regularizaciones, en el 2005; los ecuatorianos regulados representan el 20,22\% de las solicitudes (139 714), seguidos por Rumanía, Marruecos, Colombia y Bolivia con 118 298, 85 969, 56 652, 47202 regularizados respectivamente (Kostova, 2006).

7 En relación al caso concreto del Perú, el establecimiento del visado supuso el invalidar el artículo séptimo del Instrumento de Ratificación del Convenio sobre doble Nacionalidad entre España y Perú (BOE de 19 abril 1960):

los españoles y peruanos que no estuvieran acogidos a los beneficios de este Convenio, continuarán disfrutando de los derechos y ventajas que les otorguen las legislaciones peruana y española 
preferencial se fue limitando con los años al compás del endurecimiento de la política inmigratoria europea: el estricto y restrictivo control de visados y la introducción del visado de corta duración visado Schengen ${ }^{8}$ - responden tanto a intereses estatales de control de flujos como a medidas de seguridad en las fronteras del espacio Schengen.

Uno de los rasgos definitorios de las nuevas corrientes migratorias trasnacionales ${ }^{9}$ es su proceso de feminización que se relaciona con la globalización y con la privatización de la reproducción social, por la falta de incentivos que impulsen al hombre a asumir responsabilidades de cuidado en el mundo enriquecido. Cuando aludimos a la feminización no sólo nos referimos al aumento cuantitativo del número de mujeres migrantes, sino también a otros aspectos cualitativos que están transformado el tradicional modelo de acompañante dependiente a protagonista del desplazamiento o el rol que desempeñan como sustentadoras de la supervivencia o bienestar familiar (Sassen, 2003; Silvey, 2004).

No obstante, esta característica a pesar de estar plenamente asumida en la actualidad no está exenta de controversias en relación tanto a su visibilización y su significado como por el papel que asumen o desempeñan en este movimiento demográfico. En consonancia con los roles productivo y reproductivo asignados socialmente, asociados a los hombres y a las mujeres respectivamente, la emigración, como fuente de ingresos, se ha considerado secularmente como un fenómeno masculino. Por el contrario, las mujeres, visualizadas siempre como generadoras de vida -en su papel de madre y cuidadora- y en los trabajos domésticos, eran silenciadas o ignoradas en los procesos de movilidad, lo que contribuyó y contribuye a que sean más susceptibles, junto con los menores, a las distintas formas de explotación, en particular a la trata de personas (Solana, 2007; García Vazquez, 2008).

respectivamente. En consecuencia, podrán especialmente: viajar y residir en los territorios respectivos; establecerse dondequiera que lo juzguen conveniente para sus intereses...; ejercer todo género de industria; ... ejercer oficios y profesiones, gozando de protección laboral y seguridad social.

8 El día 29 de octubre de 2014 la Comisión Europea emitió dos informes favorables a la supresión del visado para estancias de corta duración para los nacionales de Perú y Colombia, al estimar que sus nacionales cumplen con los criterios para acceder sin visado al espacio Schengen. En el caso de Perú, este informe ha mostrado que la confianza en los solicitantes de visa peruana está en aumento; la migración irregular se encuentra en niveles muy bajos; los documentos de viaje peruanos son lo suficientemente seguros; las amenazas a la seguridad han retrocedido; los grupos del crimen organizado peruanos (ACG) actualmente no se les considera como una amenaza importante para la UE (con la excepción de los implicados en el tráfico de drogas); las oportunidades económicas, incluyendo un mayor comercio y flujos turísticos, se están expandiendo en paralelo con un importante crecimiento de la economía peruana; los derechos humanos y las libertades fundamentales están ahora mucho mejor protegidos y respetados en el Perú que en el pasado; la reciprocidad se garantizará y la relación entre la UE y Perú es fuerte y estable. Este proceso no concluirá antes del segundo semestre del año en curso (Comisión Europea, 2014a, 2014b).

9 El transnacionalismo es el término acuñado por la sociología de las migraciones para hacer referencia a la existencia de sólidos nexos entre los lugares de origen y destino de los inmigrantes. 
La visibilización no puede limitarse simplemente a figurar como un número en las estadísticas migratorias; por el contrario, consiste en difundir los instrumentos jurídicos internacionales en materia de derechos humanos de las mujeres y niñas migrantes, con la finalidad de prevenir las situaciones de discriminación - por mujer y por migrante- y violencia, o de denunciar ante los tribunales y la opinión pública en aquellos casos que sean vulnerados. No obstante, el esfuerzo de las organismos nacionales e internacionales implicados en la lucha contra la trata de seres humanos no alcanza las cotas de eficacia suficientes, tanto por los silencios cómplices como por la propia vulnerabilidad de las víctimas, en su mayoría con una situación administrativa compleja, la desconfianza de éstas hacia las autoridades y su gran reticencia a denunciar o colaborar (Plan, 2015-2018).

Tradicionalmente el papel de dependiente en el proyecto migratorio y la visión negativa que en ocasiones posee el imaginario colectivo, agravada en aquellos casos que se le agrega el componente de etnicidad, origina situaciones de discriminación y explotación toleradas por los instrumentos legales de extranjería y laborales, que dificultan la integración del colectivo y genera tópicos y estereotipos estigmatizantes, que, además de poder llegar a generar brotes de xenofobia y racismo, devienen en contra de la construcción de una ciudadanía inclusiva acorde con la realidad intercultural actual (Labrador, 2001; Medina, 2009; Cea y Vallés, 2009).

\section{Metodología}

Desde el punto de vista metodológico hemos recurrido a diferentes fuentes y técnicas de investigación. Por un lado, hemos usado los datos oficiales publicados por organismos públicos, y derivados de operaciones estadísticas relacionadas con los movimientos de la población y con el mercado de trabajo. Por otro lado, organizamos un grupo de discusión con mujeres inmigrantes peruanas vinculadas de alguna forma con el mundo de la pesca a través de sus parejas, tratando de seguir una metodología ampliamente utilizada en la Geografía Humana (Hernández y López, 2004).

Para el contacto con las mujeres inmigrantes hemos utilizado como enlace una institución que ellas conocen y con la que se relacionan a través del trabajo de sus parejas. Es la cofradía de pescadores San Antonio de Cambados. Gracias a su colaboración hemos obtenido información relevante sobre el proceso de contratación de los marineros peruanos y su incorporación a los barcos, principalmente dedicados al cerco. La reunión y la discusión con un grupo de estas mujeres se celebraron en las instalaciones de la cofradía el día 19 de enero de 2015.

A pesar de las reticencias iniciales, se reunió a un grupo de 8 mujeres de regiones diferentes del Perú y de edades y situaciones socio-económicas diversas. En este encuentro se realizó, en primer lugar, un cuestionario anónimo en el que incluyeron preguntas destinadas a definir su perfil en 
cuanto a origen, edad, formación, trayectoria migratoria, y percepción sobre la propia integración en la comunidad local. En segundo lugar, se entabló un debate a partir de un guión semiestructurado, con el objetivo de profundizar en su experiencia como compañeras de marineros, en relación al trabajo de sus parejas y en el contexto de una pequeña localidad de acogida situada a más de 10000 kilómetros de distancia de su país de origen. Esta discusión tenía como objetivo conseguir que las mujeres aportasen sus opiniones y tuviesen la oportunidad de contrastarlas con las de sus compatriotas, generando un intercambio de ideas. Así, el debate se organizó en cuatro bloques siguiendo un guión semi-abierto; el primero relativo al proceso migratorio, con preguntas relacionadas con la decisión de emigrar y con su trabajo en la localidad de destino. El segundo, centrado en la integración en la sociedad de acogida, donde las preguntas estaban centradas en obtener información sobre su participación en movimientos asociativos locales, su relación con otros colectivos de inmigrantes y con la sociedad en general, y sobre su trayectoria formativa relacionada con las aspiraciones a mejorar sus capacidades para acceder al mercado laboral. El tercero, sobre su percepción de la situación de la mujer en relación a su sociedad de origen. Por último, el último bloque se dedicó a cuestiones centradas en su percepción de los principales problemas a los que se enfrentan como mujeres inmigrantes y a sus perspectivas de futuro y las de sus familias.

Desde el punto de vista metodológico no se hizo un análisis del discurso (AD), entendido este como una interpretación sistemática del discurso oral puesto que se partía de la existencia de un guión semi-estructurado que permitía un vaciado de aquellos elementos representativos sin necesidad de acudir a las técnicas propias del AD.

\section{Figura 1. Localización del área de estudio.}

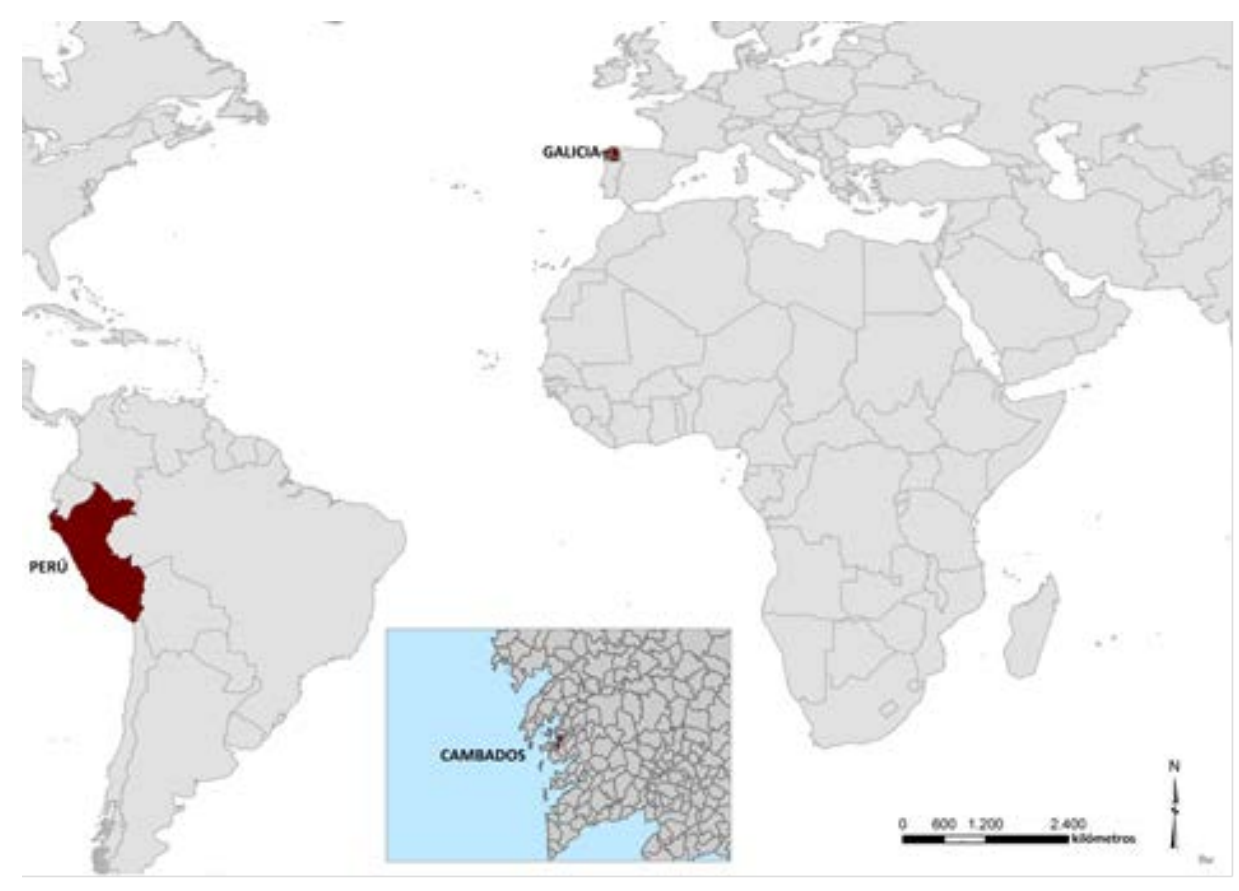

Fuente: elaboración propia 
Finalmente, para dar más contenido a la investigación y complementar la información obtenida en la primera fase, en abril de 2016 se realizaron dos entrevistas que permitieron profundizar en los detalles de la llegada y establecimiento de las familias peruanas en este municipio gallego, y en su proceso de inserción laboral. La primera de ellas se realizó a la secretaria de la Cofradía de Pescadores de San Antonio en Cambados, puesto que esta institución había participado activamente en la preparación de las ofertas laborales que permitieron las primeras y más numerosas llegadas de marineros peruanos a Cambados. La segunda, en el Instituto Nacional de la Marina, al Director Provincial de Vilagarcía de Arousa, de cuya dirección provincial dependen los afiliados al REM del municipio de Cambados, que proporcionó importante información tanto cuantitativa como cualitativa sobre este proceso.

\section{Cambados, puerto de destino}

En el sector pesquero gallego, en agosto de 2014 había 1285 extranjeros afiliados a la Seguridad Social, en el Régimen especial del Mar. De ellos el 82,1\% eran extracomunitarios, y entre los procedentes de fuera de la Unión Europea el colectivo de mayor peso era el de peruanos (186 afiliados), después del de senegaleses (201 afiliados). Su peso aún había sido mayor, tal y como recoge la encuesta Ocupesca, realizada en el 2011 por el gobierno gallego, cuándo suponían el colectivo más numeroso de extranjeros, un 3,4\% de los ocupados en la pesca en Galicia. Para este estudio hemos puesto el foco en la pequeña villa costera de Cambados, situada en la Ría de Arousa, donde ha tenido tradicionalmente un peso muy importante la pesca y el marisqueo, y por consiguiente la población activa en el sector (Pérez Sánchez, 1998). En la actualidad las actividades vinculadas a este sector aportan entre el 10 y el $20 \%$ del PIB municipal (IGE, 2015). Por otra parte, esta es una de las localidades gallegas en las que hay registrados más pescadores de origen peruano.

El municipio de Cambados cuenta con 13895 habitantes (2015), y en la cabecera municipal, homónima, se sitúa el puerto pesquero, donde tiene gran importancia la flota de cerco, que faena en el caladero litoral, constituida por más de 20 embarcaciones (Pesca de Galicia, 2015), y donde se emplearon gran parte de los peruanos llegados al municipio.

Ya hemos comentado que la elección de Cambados como ámbito de estudio responde a la importancia del colectivo de marineros peruanos en dicha localidad. La Figura 2 nos muestra la rápida progresión de la inmigración peruana en Galicia. En el año 2006, en pleno auge económico, el Observatorio Permanente de la Inmigración detectaba que Cambados era uno de los municipios gallegos que acogía a más peruanos, junto a los principales núcleos urbanos (A Coruña y Vigo) así como a los 12 grandes puertos pesqueros (además de A Coruña y Vigo, Ribeira y Burela). También señalaba que era el colectivo más numeroso en afiliaciones al Régimen Especial 
de la Seguridad Social de Trabajadores del Mar, ya que suponía más del 25 \% del total regional. Por lo tanto, parece evidente esa vinculación entre inmigración peruana y trabajo en el mar.

Figura 2. Evolución de naturales del Perú en Galicia (1996-2009)

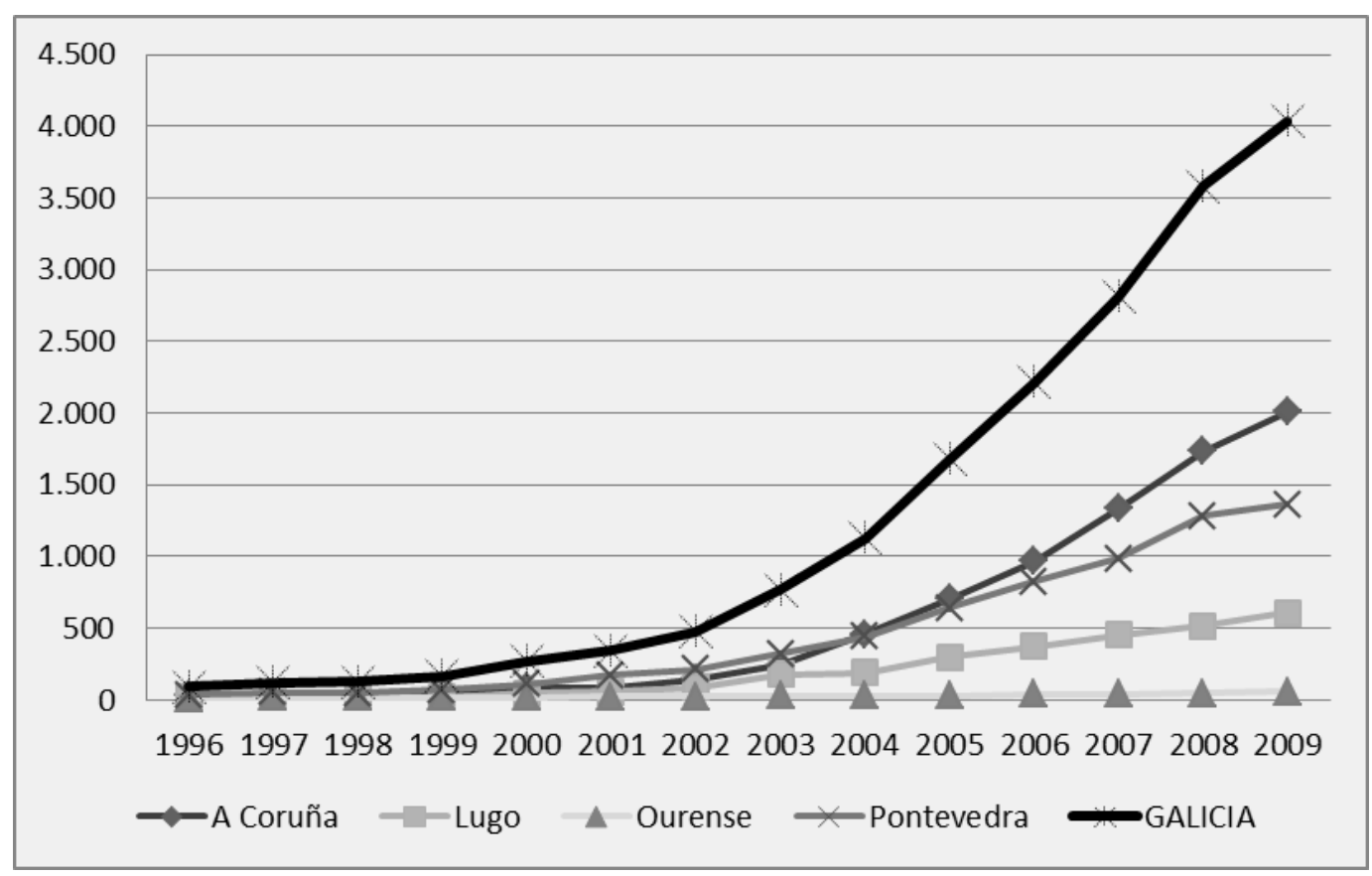

Fuente: INE

Cambados es uno de los municipios situado en la Ría de Arousa, un entorno de gran actividad turística estival, en el que el rápido crecimiento de la construcción en los años de tránsito entre los dos siglos alejó a muchos jóvenes locales de la actividad pesquera generando una demanda hasta el momento inédita de mano de obra extranjera. Recordemos además que las características de la flota de litoral de puertos de tamaño medio como el de Cambados estimuló la movilidad laboral. La flota de cerco se caracteriza por desarrollar una pesca litoral, en el caladero del Cantábrico-Noroeste, con mareas de no más de un día, pero en unas condiciones muy duras de trabajo, fundamentalmente nocturno.

En el año 2004 nos encontramos con una fuerte escasez de mano de obra en la pesca de cerco en el puerto de Cambados. Su Cofradía de Pescadores recibía numerosas quejas por parte de sus afiliados debido a que las embarcaciones debían hacerse al mar con tripulaciones formadas por el mínimo de hombres, o incluso quedarse en puerto. La dureza de las condiciones de trabajo de la pesca al cerco, los salarios reducidos, y las oportunidades de empleo en la pesca con otro tipo de artes, y en el marisqueo, dificultaban que los barcos completasen sus tripulaciones para poder salir a faenar, que como mínimo estaban formadas por ocho personas. Es en este contexto en el que, la Cofradía, junto con los armadores locales, y con el asesoramiento de la consejería competente en materia de pesca del gobierno autonómico, se decide a iniciar un proceso de reclutamiento de 
marineros peruanos en origen, a través de la embajada de España en Lima, y en el conocimiento de la existencia de convenios con este país que facilitarían los trámites administrativos para la llegada de trabajadores.

Tabla 2. Afiliados al Régimen Especial del Mar por país de origen en la Dirección Provincial de Vilagarcía de Arousa (2004-2016)

\begin{tabular}{|c|c|c|c|c|c|}
\hline Año & $\begin{array}{c}N^{\circ} \text { total } \\
\text { afiliados }\end{array}$ & $\begin{array}{c}N^{\circ} \text { afiliados } \\
\text { extranjeros }\end{array}$ & $\begin{array}{c}N^{\circ} \text { afiliados } \\
\text { peruanos }\end{array}$ & $\begin{array}{c}\text { \% peruanos/total } \\
\text { extranjeros }\end{array}$ & $\begin{array}{c}\text { Peruanos: colectivo } \\
\text { más numeroso }\end{array}$ \\
\hline 2004 & 10363 & 86 & 13 & 15 & \\
\hline 2005 & 9624 & 118 & 36 & 30,5 & \\
\hline 2006 & 9039 & 141 & 65 & 46 & \\
\hline 2007 & 8779 & 154 & 67 & 43,5 & \\
\hline 2008 & 8565 & 195 & 74 & 37,9 & \\
\hline 2009 & 8565 & 239 & 91 & 38 & \\
\hline 2010 & 8561 & 260 & 101 & 38,5 & \\
\hline 2011 & 8355 & 241 & 100 & 41,4 & \\
\hline 2012 & 8133 & 253 & 99 & 39,1 & \\
\hline 2013 & 7388 & 221 & 84 & 38 & \\
\hline 2014 & 7871 & 164 & 45 & 27,4 & \\
\hline 2015 & 7099 & 136 & 44 & 32,3 & \\
\hline 2016 & 7437 & 138 & 35 & 25,3 & \\
\hline
\end{tabular}

Fuente: ISM, Delegación provincial de Vilagarcía de Arousa. Datos del mes de febrero

Este proceso fue iniciado en 2003 a título individual por algún armador local a través del contingente de trabajadores extranjeros, regulado con carácter anual por el Ministerio correspondiente. Pero es en el año 2004 cuando la Cofradía de Pescadores se decide a realizar llamadas individualizadas de trabajo, a través de la Embajada de España en Lima, concretadas en ofertas de trabajo con una duración de 9 meses, que propiciaron la llegada a Cambados ese mismo año de una primera remesa de 45 trabajadores peruanos, procedentes fundamentalmente de la capital y El Callao, y de Chiclayo, en el Norte del país. Estos llegaban sin familia, y fueron alojados en la localidad, con la total colaboración de los armadores. En los dos años siguientes se repitieron estas ofertas de trabajo gestionadas por la Cofradía, pero a partir de ese momento la llegada de trabajadores ya dejó de estar supervisada en origen, y también comenzó un proceso de reagrupación familiar. La tabla anterior nos permite ver el progresivo incremento del peso de los 
trabajadores peruanos en el Régimen Especial del Mar, con valores en torno al 40\% de los afiliados extranjeros entre los años 2007 y 2013, y con dos repuntes en 2007 y 2011. Aunque es en el año 2010 cuando se registra el mayor número de afiliados en la delegación provincial de Vilagarcía de Arousa, donde se contabilizan los trabajadores del municipio de Cambados.

Para poder estudiar el proceso de integración de estos trabajadores y de sus familias debemos tener en cuenta que el volumen de población extranjera en Cambados es muy bajo, ya que no alcanza el $6 \%$, en un municipio donde el $70 \%$ de la población reside en el lugar en el que ha nacido (INE, 2015). Y aunque el volumen de inmigrantes no es el único factor que influye en una situación de integración o no, sí será un elemento a tener en cuenta, al igual que la coyuntura socioeconómica de la sociedad receptora, o la existencia de políticas públicas que orienten y faciliten esta integración (Giménez, 2003).

\section{Consideraciones sobre la integración social de las mujeres peruanas}

De todas las comunidades inmigrantes en Galicia (y probablemente en España) las de origen de habla hispana son las que muestran un mayor nivel de integración, por las razones ya descritas anteriormente. Como decíamos en la introducción de este artículo, el objetivo de este trabajo se centra en conocer si los roles desempeñados por las mujeres gallegas en la pesca se reproducen entre las inmigrantes, por un lado, y evaluar el nivel de integración social de las mujeres de los marineros peruanos en una comunidad pesquera gallega de tamaño medio, por otro. Para empezar, nos parece relevante señalar que, en Galicia, a diferencia de lo que ocurre en otras comunidades autónomas, no se cuenta con ningún plan específico de integración social de los inmigrantes.

Varias son las dimensiones que determinan el proceso de integración de los inmigrantes en la sociedad receptora, fundamentalmente relacionadas con aspectos jurídicos, laborales, familiares, residenciales, vecinales, educativos, sanitarios, cívicos y culturales. En los últimos años cobra pujanza la concepción de la integración como un proceso de doble vía, en el que se adaptan tanto los foráneos como los autóctonos, dejando atrás la idea de que la integración es un camino que debe recorrer solamente el inmigrante (Giménez, 2003). En este trabajo vamos a centrarnos en la percepción que las mujeres peruanas tienen de su proyecto migratorio y de su integración en la sociedad de acogida.

En Cambados, la inserción laboral de los trabajadores extranjeros vino a cubrir una necesidad de mano de obra en el sector pesquero local. No se produjo una competencia con los trabajadores autóctonos por el acceso al empleo, lo cual redujo la posibilidad de conflictos. Aunque en el momento en el que la crisis económica golpeó profundamente a la sociedad local, 
fundamentalmente en los años 2013 y 2014, se generó un clima poco favorable a la presencia de trabajadores extranjeros en la pesca.

A partir del cuestionario y las entrevistas realizadas en el municipio a las mujeres de los marineros peruanos, se deduce que por causa de la crisis económica española muchas familias habían decidido regresar a su país de origen o moverse a otro destino migratorio. Señalaron también que en el momento de flujos máximos la colonia peruana estaba compuesta por más de 200 personas en un municipio que no llega a los 15 mil habitantes.

Según nos informaron las entrevistadas, la mayor parte de sus parejas ya trabajaban como marineros en sus lugares de origen. En algunos casos en barcos japoneses de gran altura. El cierre de empresas o las condiciones laborales con ausencias muy prolongadas del hogar fueron motivos para emprender la movilidad laboral. De hecho, una de las mujeres más veteranas confesó que las mareas de varios meses fueron decisivas para emigrar, para buscar un trabajo que permitiese estar más tiempo con la familia. Esta afirmación abrió un interesante debate puesto que las entrevistadas reconocen que los salarios eran mejores en esos buques de pesca industrial, aunque desde su punto de vista no compensan los largos períodos en que sus parejas se encuentran fuera de casa. Con todo, hubo familias que decidieron irse a ciudades gallegas próximas, como Vigo, A Coruña o Ribeira, en los que tienen su base este tipo de embarcaciones con el fin de enrolarse en las mismas.

Sin embargo, el hecho de que el marido pueda dormir en casa todas las noches no hace que se sientan más satisfechas con ese tipo de trabajo. Reconocen de forma unánime que es muy duro, con muchos peligros, mal pagado, con largos períodos de inactividad y con otros de intensa carga laboral que incluye salida al mar muy temprano en la mañana para regresar muchas veces 12 horas más tarde con poca pesca. Esta opinión parece explicar que todas respondiesen de manera rotunda que no querían que sus hijos se dedicasen a esta profesión. En este sentido el comportamiento es igual al de cualquier mujer de marinero gallego cuyo rechazo llega incluso a no desear que sus hijas se casen con un hombre que trabaje en barcos pesqueros.

Las duras condiciones del trabajo en los barcos dedicados al cerco en cierta medida se ven compensadas por una mayor estabilidad frente a otros empleos que han sufrido de manera más profunda la crisis. Nos referimos fundamentalmente a la construcción, que durante muchos años fue el nicho de mercado en el que se empleaban una parte considerable de los hombres inmigrantes e incluso de la población autóctona que se desplazó hacia ese sector, frecuentemente huyendo de la pesca. Sin embargo, la vuelta parcial de estos últimos también ha tenido consecuencias negativas sobre los trabajadores inmigrantes en forma de una reducción de las oportunidades laborales.

Son también estas duras condiciones de trabajo las que, a juicio de sus mujeres hace que sean precisamente los hombres los que muestren un mayor deseo de volver a su país. Es muy difícil 
sintetizar las respuestas que surgieron del grupo de discusión en relación a la idea de quedar o marcharse a su país. Dejando claro que son ellos los menos satisfechos, a juicio de las entrevistadas, ellas mostraron una gran indefinición y muchas dudas. Quedó patente que los lazos que mantienen con su lugar de origen son fuertes y evidentes, pero también que perciben que las condiciones de vida allí continúan siendo muy difíciles.

Los descendientes son un motivo muy importante para establecerse definitivamente en Cambados. Reconocen que cuando van de vacaciones a Perú son los hijos los que peor se adaptan, tanto en términos de alimentación como de otro tipo de hábitos. El principal problema reside en aquellas mujeres cuyos hijos e hijas tienen ya una cierta edad oscilando entre la adolescencia y la juventud. En estos casos la negativa a regresar es mucho más consistente y probablemente condiciona la toma de decisiones. Una de las madres reconoció las dificultades que supone que sus hijos, ya algo mayores, no quieran regresar. Otra de las mujeres comentó la intención de su hijo de 21 años de emigrar a otra ciudad de España o a otro país del entorno. Preguntadas por el deseo de que sus hijos vayan a la universidad, la cuestión económica se vio como definitiva para excusar esa posibilidad.

Los hijos e hijas además son el principal factor de integración social. Los estudios realizados muestran que es la comunidad de habla hispana la mejor integrada en Galicia (Aldrey et al., 2008) y probablemente en España, jugando un papel importante el idioma. La situación bilingüe de este territorio no genera demasiados problemas, mucho menos a los hijos. Con todo, a pesar de llevar viviendo en Cambados entre 5 y 8 años, se evidencia una escasa participación en la vida social y cultural del pueblo que sólo tiene como excepción la escuela: la asistencia a las reuniones del colegio, las fiestas de cumpleaños u otras actividades extra-escolares sirven para que las madres entren en contacto directo con otras mujeres locales. Reconocen su poca interacción que se limita muchas veces al ámbito de sus hijos. Por el contrario, mantienen fuertes lazos entre ellas y con el resto de la comunidad peruana; de hecho, existe una asociación que consideran de referencia, aunque en estos momentos no está activa debido al gran número de personas que regresaron a su país. De todas formas, esos lazos son frecuentemente de carácter familiar y también tienen que ver con la región de país de la que proceden.

Reconocen que les gustaría estar más integradas en la sociedad y en cierta medida parecen admitir que tienen responsabilidad en ello. Por ejemplo, cuando dicen que apenas salen ya que ir a cenar o a divertirse implica un elevado gasto que, o bien no pueden afrontar, o bien les obligaría a detraerlo de otras necesidades más urgentes. Nos comentan que ese tipo de vida es la que pueden llevar los hombres solteros (en ningún caso se refirieron a mujeres solteras), que al no tener cargas familiares pueden compartir vivienda e incluso ir a Perú todos los años. Pero ellas, la mayoría con al menos 2 hijos, tienen otras prioridades. 
La economía centra buena parte de su comportamiento y de sus estrategias. A todas les gustaría trabajar, pero ninguna lo hace en estos momentos. Aunque sólo 3 de ellas trabajaban fuera de casa en su país, señalan que en Perú la economía informal da muchas más oportunidades a las mujeres que pueden obtener pequeños beneficios practicando una economía de autosubsistencia, cosa que no pueden hacer en Cambados. A parte de las dificultades derivadas de una economía en crisis, hay otros problemas a los que se tienen que enfrentar, relativos al mercado laboral. Uno de ellos es la no convalidación de sus títulos formativos lo que las sitúa en situación de mayor vulnerabilidad ante la administración y los empleadores. La encuesta nos permite observar que la mayor parte de las mujeres tiene estudios medios o superiores. Una de las más veteranas nos cuenta como su formación y experiencia como administrativa no tuvo ningún valor cuando buscó trabajo en Cambados. Otra de las intervinientes, sin duda la más integrada, con casi 10 años de estancia, nos cuenta que se tuvo que sacar de nuevo el título de esteticista en España para poder trabajar. Esta mujer era la única que disponía de carnet de conducir, lo que le da más oportunidades, y la que confesó tener unas redes sociales con personas locales más amplias; además también era la que más tiempo había trabajado, y en el momento actual no lo hacía por causa de su reciente maternidad.

En general mostraron un interés por formarse para poder acceder en mejores condiciones al mercado laboral. Muchas de ellas asistieron a cursos oficiales sobre todo relacionados con el ámbito socio-sanitario, orientados al cuidado de personas mayores. En algún caso se quejaban de que estos cursos no servían para acceder al mercado laboral, aunque se mostraban esperanzadas. Sus empleos en Cambados acostumbran a ser temporales vinculados con la demanda en hostelería durante el verano. Se quejan sobre todo de las condiciones de los contratos, cuando los hay, que no responden a la carga de trabajo real (aspecto común que afecta a la economía española) así como de unos salarios bajos, incluso menores por su condición de extranjeras.

Una de las cuestiones que más nos interesaba tenía relación con el trabajo en el mar. La mujer en Galicia ha desempeñado tradicionalmente un papel relevante en la economía marinera, como se ha citado anteriormente, desempeñando labores como la venta del pescado, el arreglo de las redes, el marisqueo a pie o el trabajo en las conserveras. Sin embargo, ninguna de las inmigrantes entrevistadas sigue esas pautas. Preguntadas por los motivos de esta situación, nos indican que la población local es muy reacia a abrir estos trabajos a las extranjeras. De hecho, varias de ellas nos comentaron que habían preguntado por la posibilidad de sacar el permiso para mariscar, y que les había dicho que eso era sólo para las del pueblo. De todas formas, también reconocieron algunas de las entrevistadas que el trabajo de mariscadora es muy duro, no se realiza de manera continuada a lo largo del año, y además los ingresos son muy escasos, afirmaciones que responden efectivamente a la realidad de esta actividad. 
Por último, la vivienda representa un elemento central de su discurso y de sus preocupaciones. Señalan que, a pesar de las dificultades de la vida en Perú, el hecho de poseer una vivienda les da una seguridad que aquí no tienen. Pagar el alquiler de una casa es una absoluta prioridad y de ahí que genere situaciones incluso de ansiedad. Hay que recordar que uno de los grandes dramas derivados de la crisis económica española son los desahucios provocados por los impagos de la vivienda. Es en este punto donde reside una de las grandes diferencias que indican las mujeres entre estar en Perú o en España. Es de destacar que la mayor parte de las mujeres entrevistadas no reciben ningún apoyo público directo, tan sólo en un caso por hijo menor a su cargo, y en otro son los servicios sociales los que dan una ayuda alimenticia.

\section{Conclusiones}

La larga discusión mantenida con las mujeres de marineros peruanos ha servido para poner en evidencia muchas cuestiones que son comunes a las personas inmigradas y otras más específicas vinculadas con la vida en el mar. Desde una perspectiva de género destacamos el escaso peso que tiene la mujer en el proceso migratorio a pesar de los cambios que se han experimentado en los últimos decenios (Taylor et al., 2006). En el caso estudiado, todas llegaron a través de la fórmula de reagrupamiento familiar, por lo tanto, condicionadas por el trabajo de sus parejas. Una vez instaladas en su nuevo destino la toma de decisiones sigue sin estar marcada por ellas. Hay dos elementos que resultan fundamentales. En primer lugar, el ya señalado trabajo de sus maridos, y, en segundo lugar, por la segunda generación, generalmente mucho más integrada y con pocos deseos de mudarse. Por lo tanto, en nuestro caso se sigue manteniendo el modelo tradicional de desplazamiento en el que la mujer tiene un rol dependiente.

Este modelo tradicional de dependencia no quita para que se detecten ciertas singularidades, relacionadas con la ocupación laboral de los maridos, que refuerzan esa dependencia. La intensa jornada laboral en los barcos de cerco, que empieza a horas muy tempranas de la mañana y se prolonga hasta la tarde obliga a muchas mujeres a permanecer en la casa para poder atender a los hijos. De hecho, en la discusión señalaron que en ocasiones tienen que renunciar a sus trabajos fuera del hogar porque contratar a una persona para cuidar de los descendientes consumiría una parte muy importante de sus reducidos salarios. Esta situación se hace más evidente porque la temporada alta turística del verano, cuando se necesita mano de obra para la hostelería, coincide con uno de los períodos de máxima actividad de la flota de cerco y también con el período de vacaciones escolares. Evidentemente el problema se agudizaría en los barcos de altura y gran altura, en donde las ausencias prolongadas del hombre prácticamente imposibilitan el trabajo remunerado de la mujer. La posibilidad de trabajar en la flota artesanal o en los barcos mejilloneros, siempre cerca de la costa, con horarios más amables y en menores condiciones de riesgo no es 
contemplada como opción por las mujeres de los marineros, ya que ese tipo de puestos sigue reservado para los círculos familiares de los pequeños empresarios gallegos.

En nuestro estudio de caso con mujeres inmigrantes vinculadas a través de sus parejas con el mundo del mar, se han demostrado comportamientos generales y particulares de este colectivo. Por un lado, la perspectiva de género permite establecer similitudes con el resto de las inmigrantes. Es decir, su invisibilización (Durán, 2009; Gregorio, 1998), que se evidencia en la fuerte dependencia con respecto a las decisiones de sus maridos en primer lugar, y de la descendencia en segundo lugar. Sus expectativas laborales y aquellas que tienen que ver con su futuro vital están fuertemente condicionadas por los deseos y decisiones del resto de la familia.

Por otro lado, su vinculación con el mundo de la pesca introduce algunos elementos singulares. Probablemente el más significativo es que los ritmos diarios y anuales de la actividad pesquera son un obstáculo mayor, que se suma al de mujer e inmigrante, para el acceso a un puesto de trabajo. Además, las opciones laborales en el ámbito de la pesca, a las que se dedican muchas mujeres locales, están cerradas para ellas.

Aunque pudiera parecer que la integración social en una localidad de tamaño pequeño es más fácil que en una gran ciudad, esta investigación ha puesto en evidencia las complicaciones a las que se tienen que enfrentar. Aunque es cierto que una parte de éstas tienen que ver con su condición de mujer inmigrante, otra parte está relacionada con el trabajo que ejercen sus parejas en el mar, que introduce todavía más dificultades y obstáculos a su situación.

Este trabajo es, en definitiva, una primera aproximación desde la perspectiva de género al mundo de las personas inmigradas que trabajan en la pesca. Se trata de un colectivo pequeño en tamaño, pero con ciertas singularidades. En el caso de Galicia hay un importante antecedente en el norte de la comunidad autónoma, en Burela-Lugo, en donde los trabajadores caboverdianos que llegaron para trabajar en la construcción de la fábrica de alúmina-aluminio en la década de 1970 pasaron muchos de ellos a emplearse en los barcos boniteros. En la actualidad éste representa un ejemplo de integración en el que las mujeres desempeñan un papel muy activo (Oca, 2013). Falta por ver hasta qué punto se pueden reproducir estos esquemas considerando que las variables espaciotemporales entre los dos casos son muy diferentes. Este es un desafío para abordar en futuras investigaciones. 


\section{Bibliografía}

Alcaide, J. (1967). Sector Pesquero: su importancia y evolución. Información Comercial Española, $417,55-60$.

Aldrey, J. A., González Pérez, J., y Santos, X. (Dirs.) (2008). A inmigración estranxeira en Galicia. Santiago: Xunta de Galicia.

Aldrey, J. A., y Durán, F.R. (2011). As novas tendencias na poboación galega: da emigración á inmigración. En Ma. J. Piñeira y X. Santos (Coords.), Xeografía de Galicia (pp. 229-277). Vigo: Xerais.

Castles, S., y Kosack, G. (1973). Immigrant workers and class structure in Western Europe. Londres: Oxford University Press.

Castles, S. (2010). Understanding Global Migration: A Social Transformation Perspective. Journal of Ethnic and Migration Studies, 36(10), 1565-1586.

Cea, M. A., y Valles, S. (2009). Evolución del racismo y la xenofobia en España. Madrid: Ministerio de Trabajo e Inmigración.

Comisión Europea (2016a). La política pesquera común en cifras y datos. Bruselas: Unión Europea.

Comisión Europea (2016b). Study on the employment of non-local labour in the fisheries sector. Bruselas: Unión Europea.

Comisión Europea (2014a). Informe de la Comisión al Parlamento Europeo y al Consejo sobre el cumplimiento por parte de Colombia de los criterios pertinentes con vistas a la negociación de un acuerdo de exención de visado entre la Unión Europea y Colombia. Bruselas: Unión Europea. 29.10.2014 COM(2014). [SWD(2014) 329 final].

Comisión Europea (2014b). Informe de la Comisión al Parlamento Europeo y al Consejo sobre el cumplimiento por parte de Perú de los criterios pertinentes con vistas a la negociación de un acuerdo de exención de visado entre la Unión Europea y Perú. Bruselas: Unión Europea. 29.10.2014 COM(2014). [SWD(2014) 328 final].

Cruz Villalón, J. et al. (1994). Mujer y agricultura en España: género, trabajo y contexto regional. Vilassar de Mar: Oikos-Tau.

Devoto, F. (1992). Movimientos migratorios: historiografía y problemas. Buenos Aires: Centro Editorial de América Latina.

Domingo, C. (2004). Inmigración y fecundidad en España. Cuadernos Geográficos, 76, 239-250. 
Durán, F. R. (2009). La exportación invisible: mujeres españolas emigrantes. En A. Liñares (Coord.), El protagonismo de la mujer en las corrientes migratorias españolas (pp. 39-62). Vigo: Grupo España Exterior.

Etxaluze, A. (2000). La falta de tripulaciones en el sector pesquero. Revista de Estudios Marítimos del País Vasco, 3, 593-605.

FAO (1975). El estado mundial de la pesca y la acuicultura. Roma: FAO.

Fernández Casanova, C. (coord.) (1998). Historia da pesca en Galicia. Santiago: Servicio de Publicacións da Universidade de Santiago de Compostela.

Fernández Vidal, D., y Muiño, R. (2014). Fact or fiction? Assessing governance and comanagement of Marine Reserves of Fishing Interest in Cedeira and Lira (NW Spain). Marine Policy, $47,15-22$.

Gago, C. (Coord.) (2004). La mujer en el mundo de la pesca en Galicia. Santiago: Consellería de Pesca e Asuntos Marítimos.

García Allut, A. (2005). Mardelira: mariñeiros con Proxecto. Interea visual, 4, 53-56.

García Allut, A. (1998). Os Pescadores como creadores de coñecemento "experto", o seu papel no deseño de novas políticas pesqueiras. En Antropoloxía mariñeira: actas do Simposio Internacional in memoriam Xosé Filgueira Valverde (pp. 57-75). Santiago de Compostela: Consello da Cultura Galega.

García Negro, M. C. (2005). Participación das mulleres na pesca actual. Forza laboral e papel económico. En Actas del Simposio Aktea (pp. 71-79). Santiago de Compostela, 4-6 de febrero de 2004.

García Negro, M. C., y Zotes Tarrío, Y. (2006). El trabajo de las mujeres en el sector pesquero gallego: análisis de los problemas relacionados con su tratamiento estadístico. Revista Galega de Economía, 15(1), 101-124.

García-Ramón, Ma . D. (1989). Para no excluir del estudio a la mitad del género humano: un desafío pendiente en Geografía Humana. Boletín de la Asociación de Geógrafos Españoles, 9, 27-48.

González Pérez, J. (2008). Inmigración estranxeira e territorio en Galicia. Santiago: Xunta de Galicia.

González Pérez, J. (2010). La primera generación de extranjeros inmigrantes en Galicia. Condiciones de vida y relación con el destino según los colectivos estudiados. Migraciones, 28, 87-125.

Gregorio, C. (1998). Migración femenina. Su impacto en las relaciones de género. Madrid: Narcea. 
Hernández Borge, J., y López González, R. (2004). Análise dunha experiencia migratoria feminina a través das fontes orais. Xeografía, 4, 191-198.

Hernández Borge, J. (2007). La población del sector pesquero en Galicia. En S. Gutiérrez Ronco y J. J. Sanz Donaire (Coords.), Homenaje al Profesor José Manuel Casas Torres (pp. 307-317). Madrid: Universidad Complutense.

IGE (2015). Análise do sector da pesca. Santiago de Compostela: Instituto Galego de Estatística. Izquierdo, A., López de Lera, D.m y Martínez Buján, R. (2002). Los Preferidos del siglo XXI: la inmigración latinoamericana en España. En F. J. García Castaño y C. Muriel (Coords.), La inmigración en España. Contextos y alternativas (pp. 237-248). Granada: Universidad y Laboratorio de estudios interculturales.

Kostova, M. (2006). Una evaluación del último proceso de regularización de trabajadores extranjeros en España (febrero-mayo 2005). Un año después. Madrid: Real Instituto Elcano.

Labrador, J. (2001). Identidad e inmigración. Un estudio cualitativo de inmigrantes peruanos en Madrid. Madrid: U. Comillas.

Lobo, M. (1967). La flota pesquera española y su desarrollo. Información Comercial Española, $471,67-74$.

Lois, R. C. (1999). La pesca: actividad económica y organización espacial. En R. Galdós y E. Ruiz (Coords.), Postproductivismo y Medio Ambiente. Perspectivas geográficas sobre el espacio rural. IX Coloquio de Geografía Rural. Ponencias, Informes Técnicos, $n^{\circ} 82$ (pp. 113-175). Vitoria: Departamento de Agricultura y Pesca, Gobierno Vasco.

Mabogunje, A. (1970). System approach to a theory of rural-urban migration. Geographical Analysis, 2(1), 1-18.

Maguid, A., y Cerrutti, M. (2010). Emigrantes sudamericanos en España: contextos de origen y diversidad socioeconómica. En Actas IV Congreso de la Asociación Latinoamericana de Población (ALAP). La Habana, Cuba.

Martínez Ferreiro, R. et al. (1998). Síntese histórica do marisqueo en Galicia. En Marisqueo en Galicia. 3as Xornadas de Medio Mariño e Acuicultura. A Coruña: Edicións do Castro.

Marugán, B. (2010). Y cogieron ese tren... profesionalización de las mariscadoras gallegas. Santiago: Consello da Cultura Galega.

Marugán, B. (2010b). A importancia das mulleres na pesca galega. En M. C. García-Negro (Coord.), Economía pesqueira: achegas desde un curso universitario (pp. 415-437). Santiago de Compostela: Sotelo Blanco. 
Medina, R. (2009). La política de la inmigración europea y la ilegalidad de la inmigración. En A. González (Ed.), Lugares, procesos y migrantes. Aspectos de la migración colombiana (pp. 51-82). Bruselas: P. I. E. Peter Lang.

Oca, L. (2013). Caboverdianas en Burela (1978/2008): migración, relación de xénero e intervención social (Tesis doctoral). Santiago: Universidad de Santiago de Compostela.

Pedone, C. (2002). El potencial del análisis de las cadenas y redes migratorias en las migraciones internacionales contemporáneas. En F. J. García Castaño y C. Muriel López (Eds.), Actas del III Congreso sobre la inmigración en España. Contextos y alternativas (pp. 223-235). Granada: Laboratorio de Estudios Interculturales.

Pedone, C. (2008). "Varones aventureros" vs." Madres que abandonan": reconstrucción de las relaciones familiares a partir de la migración ecuatoriana. Revista Interdisciplinaria da Mobilidade Humana REMHU, 16(30), 45-64.

Penas, X. (1998). Marisqueo en Galicia. A Coruña: Edicións do Castro.

Pérez Pazó, X. (2010). O marisqueo en Galicia. En M ${ }^{a}$ C. García Negro (Coord.), Economía Pesqueira. Achegas desde un curso universitario (pp. 319-330). Santiago: Sotelo Blanco.

Pérez Sánchez, J. A. (1988). Las Actividades agropecuarias y pesqueras en la margen derecha de la Ría de Arosa. A Coruña: Diputación Provincial.

Piñeiro, $M^{a}$. A., Santos, X. y Piñeira, $M^{a}$ J. (2010). Informe de buenas prácticas: diversificación orientada al turismo. En La pesca de bajura en 2007 y perspectivas para una orientación sostenible (pp. 434-469). Vigo: Centro Tecnológico del Mar.

Piñeiro, Ma. A. (2015). A Política Pesqueira Común e as comunidades costeiras de Galicia. Visións desde a Xeografía (Tesis doctoral). Santiago: Universidad de Santiago de Compostela.

Proyecto Áncora (2012). Guía para el desarrollo de iniciativas de turismo pesquero. A Coruña: Fundación Paideia Galiza.

Proyecto Áncora (2012b). Manual de buenas prácticas ambientales en el turismo pesquero. A Coruña: Fundación Paideia Galiza.

Reques, P., y Cos, O. de (2002). La emigración olvidada: la diáspora española en la actualidad. Papeles de Geografía, 37, 199-216.

Romero, A. (2000). Salgadeiras e conserveiras de pescado en Galicia: evolución histórica e o traballo das mulleres. A Coruña: Federación de Alimentación, Bebidas e Tabacos de Galicia, UGT.

Santasmarinas, P. (2010). Proceso de profesionalización das mariscadoras galegas. En M. ${ }^{a}$. García Negro (Coord.) Economía pesqueira. Achegas desde un curso universitario (pp. 331-340). Santiago, Sotelo Blanco. 
Santos, X. (2001). La explotación de recursos marinos. En La dinámica litoral-interior, Ponencias del XV Congreso de Geógrafos Españoles (pp. 213-254). Santiago: Departamento de Geografía de la Universidad de Santiago y AGE.

Santos, X. (2014). A geografia do gênero e das sexualidades na produção científica de revistas espanholas. En M. Silva y J. Silva (Orgs.) Interseccionalidades, gênero e sexualidades na análise espacial (pp. 209-228). Ponta Grossa: Todapalavra Editora.

Santos, X. (2016). Los estudios de género y sexualidad en España a través de las revistas de Geografía (1990-2014). Documents d'Anàlisi Geográfica, 62, 427-448.

Sassen, S. (2003). Contrageografias de la globalización: género y ciudadanía en los circuitos transfronterizos. Madrid: Traficantes de Sueños

Silvey, R. (2004). Power, Difference, and Mobility: Feminist Advances in Migration Studies. Progress in Human Geography, 28(4), 490-506. .

Solana, J. L. (2007). Movimientos migratorios, trabajadoras inmigrantes y empleo en la prostitución. Documentación Social, 144, 37-57.

Solsona, M. (1989). El problema de medición del trabajo de la mujer. Documents d'Anàlisi Geográfica, 14, 149-169.

Suárez Villegas, J. C. (2013). La mujer inmigrante en la cultura patriarcal y su reflejo en los medios de comunicación. Sphera Pública, 13(1), 77-94.

Taylor, M. J, Moran-Taylor M. J., y Ruiz D. R. (2006). Land, ethnic and gender change: Transnational migration and its effects on Guatemalan lives and landscapes. Geoforum, 37, 41-61.

Vallejo, R. (2003). Historia da pesca en Galicia: das orixes ata o século XVIII. Pontevedra, 19, 153178.

Varela, M., Surís, J. C., Garza, Ma. D., Iglesias, C., y Otero, Ma. S. (1997). Impacto en el sector pesquero gallego de las nuevas tendencias comerciales. Serie Estudios Sectoriales 13. Santiago: Fundación Caixa Galicia.

Varela, M. (coord.) (2003). La pesca gallega en el escenario internacional. Santiago: Fundación Caixa Galicia.

Varela, M. (coord.), (2010). Unha estratexia marítima para Galicia. Vigo: Galaxia.

Villares Paz, R., y Fernández, M. (1996). Historia da emigración galega a América. Xunta de Galicia: Santiago de Compostela.

Xunta de Galicia (2012). Enquisa sobre a poboación ocupada nos sectores da pesca e da acuicultura mariña en Galicia (OCUPESCA). Santiago: Xunta de Galicia. 
Xunta de Galicia (2013). Enquisa sobre a poboación ocupada nos sectores da pesca e da acuicultura mariña en Galicia (OCUPESCA). Santiago: Xunta de Galicia.

Zlotnik, H. (1992). Empirical identification of international migration systems. En M. Kritz, L. Lim y H. Zlotnik (Eds.), International Migration Systems: A Global Approach (pp. 19-40). Oxford: Clarendon Press. 